\title{
Digital Procedures Compared to Conventional Gypsum Casts in the Manufacturing of CAD/CAM Adhesive Restorations: 3D Surface Trueness and Interfacial Adaptation Analysis
}

\author{
Andrea Baldi ${ }^{1}{ }^{\circledR}$, Allegra Comba ${ }^{1}\left(\right.$, , Edoardo Alberto Vergano ${ }^{1}$, Michail L. Vakalis ${ }^{1}$, Mario Alovisi ${ }^{1}{ }^{\circledR}$, \\ Damiano Pasqualini ${ }^{1}{ }^{(10}$, Giorgio Ferrero ${ }^{1}$, Edoardo Italia ${ }^{1}$, Riccardo Michelotto Tempesta ${ }^{1}$, Domenico Baldi ${ }^{2}$ \\ and Nicola Scotti $1, *$ (D) \\ 1 Department of Surgical Sciences, Dental School, 10126 Turin, Italy; andrea.baldi@unito.it (A.B.); \\ allegra.comba@unito.it (A.C.); edoardo.vergano@gmail.com (E.A.V.); m.l.vakalis@gmail.com (M.L.V.); \\ mario.alovisi@unito.it (M.A.); damiano.pasqualini@unito.it (D.P.); giorgio.ferrero.doc@gmail.com (G.F.); \\ italiaedoardo@gmail.com (E.I.); riccardo.tempesta@hotmail.it (R.M.T.) \\ 2 Department of Surgical Sciences (DISC), Division of Prosthetic Dentistry, University of Genoa, \\ 16126 Genoa, Italy; baldi.domenico@libero.it \\ * Correspondence: nicola.scotti@unito.it
}

check for updates

Citation: Baldi, A.; Comba, A.; Vergano, E.A.; Vakalis, M.L.; Alovisi, M.; Pasqualini, D.; Ferrero, G.; Italia, E.; Tempesta, R.M.; Baldi, D.; et al. Digital Procedures Compared to Conventional Gypsum Casts in the Manufacturing of CAD/CAM Adhesive Restorations: 3D Surface Trueness and Interfacial Adaptation Analysis. Appl. Sci. 2021, 11, 5060. https://doi.org/10.3390/ app11115060

Academic Editor: George Eliades

Received: 14 April 2021

Accepted: 25 May 2021

Published: 30 May 2021

Publisher's Note: MDPI stays neutral with regard to jurisdictional claims in published maps and institutional affiliations.

Copyright: (c) 2021 by the authors. Licensee MDPI, Basel, Switzerland. This article is an open access article distributed under the terms and conditions of the Creative Commons Attribution (CC BY) license (https:// creativecommons.org/licenses/by/ $4.0 /)$.

\begin{abstract}
Objective. The purpose of this ex vivo study was to compare the trueness of traditional and digital workflows and to analyze the interfacial fit of CAD/CAM restorations on gypsum and 3D-printed casts (3DC). Methods: Forty patients underwent indirect posterior adhesive restorations. After tooth preparation, both traditional and chairside procedures were followed. Obtained models were scanned to generate STL files of the intraoral impression (IOS), the conventional cast (RS), and the 3D-printed cast (3DCS). Superimposition of the casts was performed to evaluate trueness. Then, for each preparation, two identical CAD/CAM restorations were milled and luted on RS and 3DC. Micro-CT scan was performed to evaluate 3D interfacial fit. Results. Surface trueness analysis showed no significant differences among groups $(p>0.05)$, with average trueness ranging from 11.56 to $17.01 \mu \mathrm{m}$. Micro-CT analysis showed significant differences between gypsum casts (average ranging from 135.78 to $212.31 \mu \mathrm{m}$ ) and 3DC (average ranging from 57.63 to $144.55 \mu \mathrm{m}$ ) for both marginal and internal fit. Conclusions. In adhesive restorations manufacturing, digital and conventional procedures generate casts that are not significantly different. Marginal fit of adhesive restorations is similar to conventional crown design and clinically acceptable. It is assumable that a direct digital workflow could benefit from the usage of 3DC.
\end{abstract}

Keywords: intraoral scanner; CAD-CAM; model 3D printing; indirect adhesive restorations; trueness

\section{Introduction}

Computer-assisted design/manufacturing (CAD/CAM) systems have made single tooth indirect restoration easier, faster, and more predictable [1,2]. Intraoral scanning and milling devices allow simple and fast digital impressions, thus enabling the projection, customization, and finally, milling of the restorations in the same appointment (chairside protocol), with consequent reduction of costs and patient discomfort [3]. The CAD-CAM workflow could also be implemented thanks to the possibility to export the stereolithography (STL) file of the intraoral scan and produce 3D printed casts (3DCs), which could be useful to clinicians and technicians for material characterization, contact points, and occlusion checks $[4,5]$. A single-tooth indirect adhesive restoration can be performed using different processes.

The traditional workflow is still frequently used and yet considered by many authors and clinicians the gold standard model for the manufacturing of adhesive restorations $[6,7]$. Conventional impressions and casts rely on high-performance materials $[8,9]$, as polyvinyl 
siloxane and type IV gypsum show great stability and precision [10] and give the possibility of layering, ultimately enhancing aesthetic outcome with good long-term performances [11,12]. However, the precision of the master cast is technique-dependent [13] and the operator skill and experience play an important role [14]. Moreover, the use of these materials presents the risk of distortion, expansion, or shrinkage due to numerous steps involved. Additionally, they need large storage spaces and there is a risk of damage during time $[15,16]$.

The most common application of CAD/CAM in dentistry is the digital acquisition of gypsum casts with the use of extraoral scanners in the dental laboratory. Even though this path may add digitalization errors to the traditional procedure, it is still considered the most trusted method when using a digital workflow is needed in order to employ certain materials [17].

The direct digital workflow with intraoral scans (IOS), on the other hand, presents several advantages; it does not involve chemical reactions, has no storage or recovery issue, and requires less time and fewer steps (no tray selection, wait time, cast setting time, disinfection, or transport). Additionally, it enables real-time evaluation of thickness, undercut, and margin [18]. Recently developed systems obviated the need for powder and reduced the discomfort by the miniaturization of intraoral cameras. However, IOS precision and accuracy is affected by patient movement, saliva, and blood [19], particularly in full-arch scans $[20,21]$. Additionally, the utilization of IOS is limited by its steep learning curve and high cost [22].

Both digital and conventional workflows can achieve clinically acceptable results for single crowns and short-fixed prostheses in terms of fit $[17,23,24]$. Fitting of the restorations is closely related to trueness and accuracy of the master cast, and it is considered a key factor for the long-term prognosis of a restoration. As a defect, it can result in decreased mechanical properties, increased plaque accumulation, and, consequently, an increased risk of caries and periodontal disease $[25,26]$. In the present paper, according to ISO 5725-1, "trueness", one of the evaluations of the general term "accuracy", is used to describe the closeness of a measurement to the actual (true) value. The trueness of digital scans has been investigated by surface deviation analysis, with superimposition on a reference model using best fit algorithms [27]. The accuracy of digital scans varies between IOS and conventional impressions, but the deviations have been reported to be minimal for up to 10 teeth in vivo 6 .

Previous studies also showed that 3D-printed casts (3DCs) nowadays have good performances in terms of accuracy, reproducibility, and precision [28]. This can be compared to traditional casts for single-tooth crowns [27,29].

Despite the presence in the literature of many studies about conventional crowns, few comparative analyses between traditional and chairside workflows for the manufacturing of single tooth adhesive restorations have been published. Thus, the aim of this ex vivo study was to compare the digital procedures, chairside or implemented with a 3DC, to the conventional workflow, analyzing the trueness of the obtained impressions/scans, (1) and the interfacial fit of the adhesive restorations to the obtained casts (2). The null hypothesis is that there are no differences between the trueness of the scans (1) and the interfacial fit of the adhesive restorations to the corresponding casts (2) fabricated by analogue and digital workflow.

\section{Materials and Methods}

\subsection{Sample Teeth Selection and Preparation}

The study was granted ethics approval by the local ethics committee at the Dental School, University of Turin (DS-2018_No. 001). Forty patients $(n=40)$ afferent to the Department of Cariology and Operative Dentistry (Dental School Lingotto, University of Turin, Turin, Italy) that needed indirect adhesive restorations of endodontically treated posterior teeth were recruited. The inclusion criteria were the following: occlusal stability, age 18-65 years, good general health, and good oral hygiene (full-mouth plaque score 
(FMPS) $<20 \%$ ). The exclusion criteria were the following: impossibility of field isolation, known allergy to the materials of the protocol, periodontal issues (advanced periodontitis, tooth mobility grade $>1$, or FMPS $>20 \%$ ), severe occlusion problem, orthodontic treatment, reduction of Vertical Dimension of Occlusion (VDO), and absence of an antagonist tooth. Periodontal scaling was performed, if needed, to obtain healthy marginal tissues.

All clinical procedures were performed by a single expert clinician using a standardized minimally invasive protocol under rubber dam isolation, as following: hard tissues detersion, cavity finishing, residual wall evaluation (covered if thickness $\leq 2 \mathrm{~mm}$ ), adhesive application according to the manufacturer's instructions (Clearfil SE Bond 2; Kuraray, Tokyo, Japan), and composite build-up (Filtek Bulk Fill Posterior; 3M, St. Paul, MN, USA) with incremental layering. The selected posterior teeth were prepared for adhesive restorations, using bevelled butt-joint design. The thickness was maintained uniform accordingly to the recommendations of the manufacturer of the employed material. Finally, finishing and polishing were performed with rubber points.

\subsection{STL Files Setup}

After rubber dam removal, IOS was performed using Cerec Omnicam (Dentsply Sirona, York, PA, USA) according to manufacturer's instructions (no direct light and saliva control [30]). An STL file, with setting "highest quality", was exported for surface analysis.

Thereafter, a conventional impression was taken with a single-phase bicomponent technique, using a flexible dual arch tray (Triple Tray; Premier Dental, Norristown, PA, USA) and polyvinylsiloxane (Express Putty and Light Regular; 3M, St. Paul, MN, USA), following manufacturer's instructions. Impressions were disinfected and sent to a dental laboratory and poured with scannable type IV gypsum (Uni-Base 300; Dentona AG, Dortmund, Germany). After setting for $96 \mathrm{~h}$ [31], conventional casts were scanned by an expert dental technician using a calibrated laboratory scanner (Sinergia Scan; Nobil-Metal, Villafranca d'Asti, Italy) with Optical RevEng Dental 2.0 software (Open Technologies, Rezzato BS, Italy) in order to obtain a reference scan (RS).

The same procedure was applied to impressions as well. Unfortunately, 16 of the scanned impressions resulted in poor-quality STL files. This can be explained by the fact that adhesive preparations often have supra-equatorial margins, consequently resulting in natural undercuts in the impression that create "shadow zones" during scanning. For this reason, scans of the conventional impressions were excluded from this study.

Finally, 3DC were produced with multi-jet printing (MJP 2500 Plus; 3D Systems, Rock Hill, SC, USA) using STL files derived from IOS, after elaboration with 3D Sprint software (3D Systems, Rock Hill, SC, USA). Resolution was set at 800, 900, and 790 Dots Per Inch (DPI) and $32 \mathrm{~m}$ layers. A dental resin material commonly used for 3DC (VisiJet M2R-TN; 3D Systems) was employed. Afterwards, 3DC were digitalized with the same protocol and scanner described above, in order to generate STL files (3D-printed cast scans; 3DCS). A summary of the study design is shown in Figure 1.

\subsection{D Surface Trueness Analysis}

Three STL files (RS, IOS, and 3DCS) for each patient were imported into Geomagic software (Geomagic Qualify 12; 3D Systems, Rock Hill, SC, USA), aligned, and manually trimmed along the prepared tooth margins to enhance superimposition precision. Only the preparation area was considered in the analysis. Trimmed files were aligned again on Geomagic Control X 2017 software (3D Systems, Rock Hill, SC, USA) using feature recognition function, followed by application of the best fit algorithm with following parameters: sampling ratio $=100 \%$, no maximum iteration, tolerance (default) $=10 \mu \mathrm{m}$. RS was used as reference for all superimpositions. A color-coded 3D surface deviation map was generated, and data of average deviation, expressed in microns, were collected in order to analyze the trueness of IOS and 3DCS compared to RS [32,33], as shown in Figure 2. 


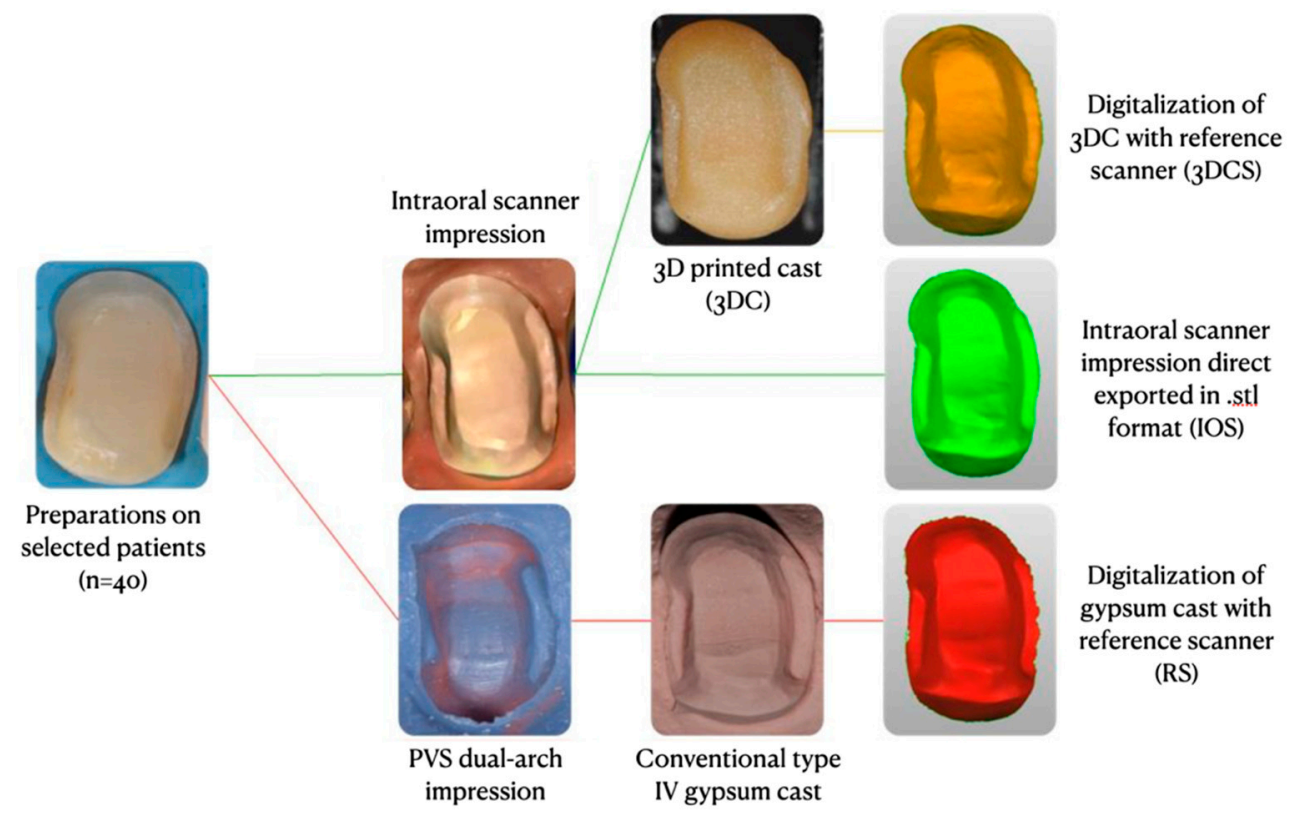

Figure 1. Summary of the study design.

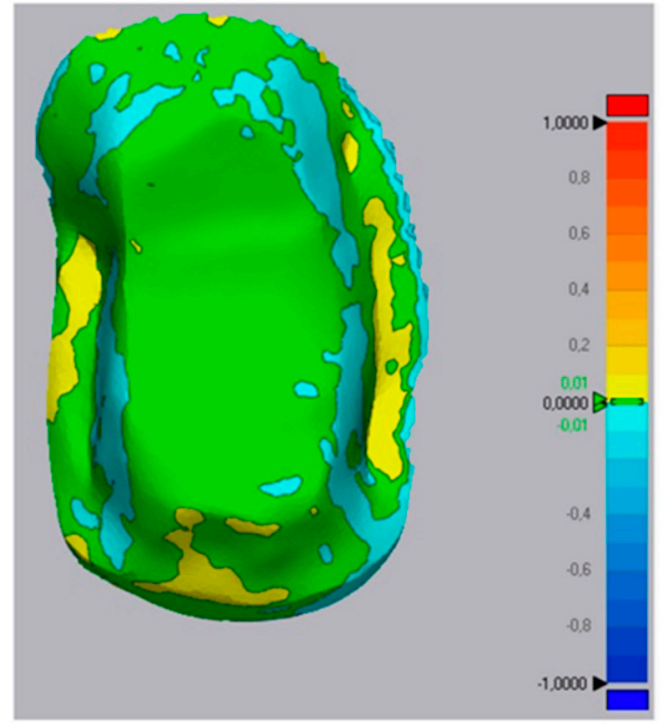

Comparison between RS and IOS

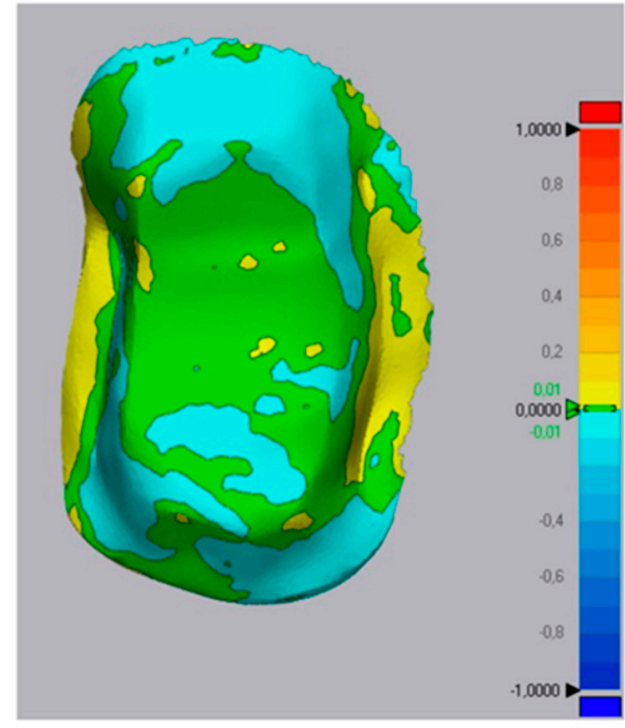

Comparison between RS and $3 \mathrm{DC}$

Figure 2. Random sample analysis. The image on the left represents the comparison between RS and IOS, while the image on the right between RS and 3DC. The tolerance of $10 \mu \mathrm{m}$ is shown in green, while other values scale from yellow to red (positive discrepancy up to $1 \mathrm{~mm}$ ) and from cyan to blue (negative discrepancy up to $-1 \mathrm{~mm}$ ).

\subsection{Interfacial Adaptation Evaluation}

Individual restorations for each preparation were projected in Cerec CAD software (ver. 4.5.2; Dentsply Sirona, York, PA, USA), setting digital spacing $=100 \mu \mathrm{m}$ only in axial and occlusal areas. Restorations were milled twice using a calibrated Cerec MC XL (Dentsply Sirona, York, PA, USA) and a hybrid ceramic, Cerasmart (GC, Tokyo, Japan) as material. After finishing and polishing, restorations were bonded onto conventional casts and 3DC using a radiopaque composite resin flow (Herculite XRV Ultra Flow; Kerr, Orange, CA, USA) and light-cured for $60 \mathrm{~s}$ with a light-emitting diode (LED) curing light (VALO; Ultradent, South Jordan, UT, USA). The aim of luting restorations to 3DC was to evaluate the precision of projecting and milling procedures, as both $3 \mathrm{DC}$ and restorations 
were designed and realized starting from the same IOS. The aim of luting restorations to conventional gypsum casts was to evaluate interfacial adaptation of chairside restorations on the gold standard model.

After re-polishing, samples were subjected to micro-computed tomography (microCT) (Skyscan 1172; Bruker, Billerica, MA, USA) to evaluate interfacial fit to conventional casts and 3DC. High-resolution scans were performed using the following settings: voltage, $100 \mathrm{kV}$; current, $100 \mu \mathrm{a}$; source to object distance, $220 \mathrm{~mm}$; pixel binning, 292; total scan duration, $40 \mathrm{~min}$; Aluminium and Copper $(\mathrm{Al}+\mathrm{Cu})$ filter; pixel size, $15 \mu \mathrm{m}$; and rotation 0.5. An NRecon (Scanco Medical, Brüttisellen, Switzerland) was used to reconstruct samples to obtain DCM files using the same Hounsfield unit (HU) parameters for all samples.

A novel 3D method was used to analyze overlay fit. Using Mimics software (ver. 20.0; Materialise, Ann Arbor, MI, USA), thresholding of the radiopaque flow was performed automatically in order to generate STL masks for each cast. These files were imported into Geomagic Control $X$ for 3D thickness analysis using default settings in order to determine marginal and internal interfacial adaptation, as shown in Figure 3.
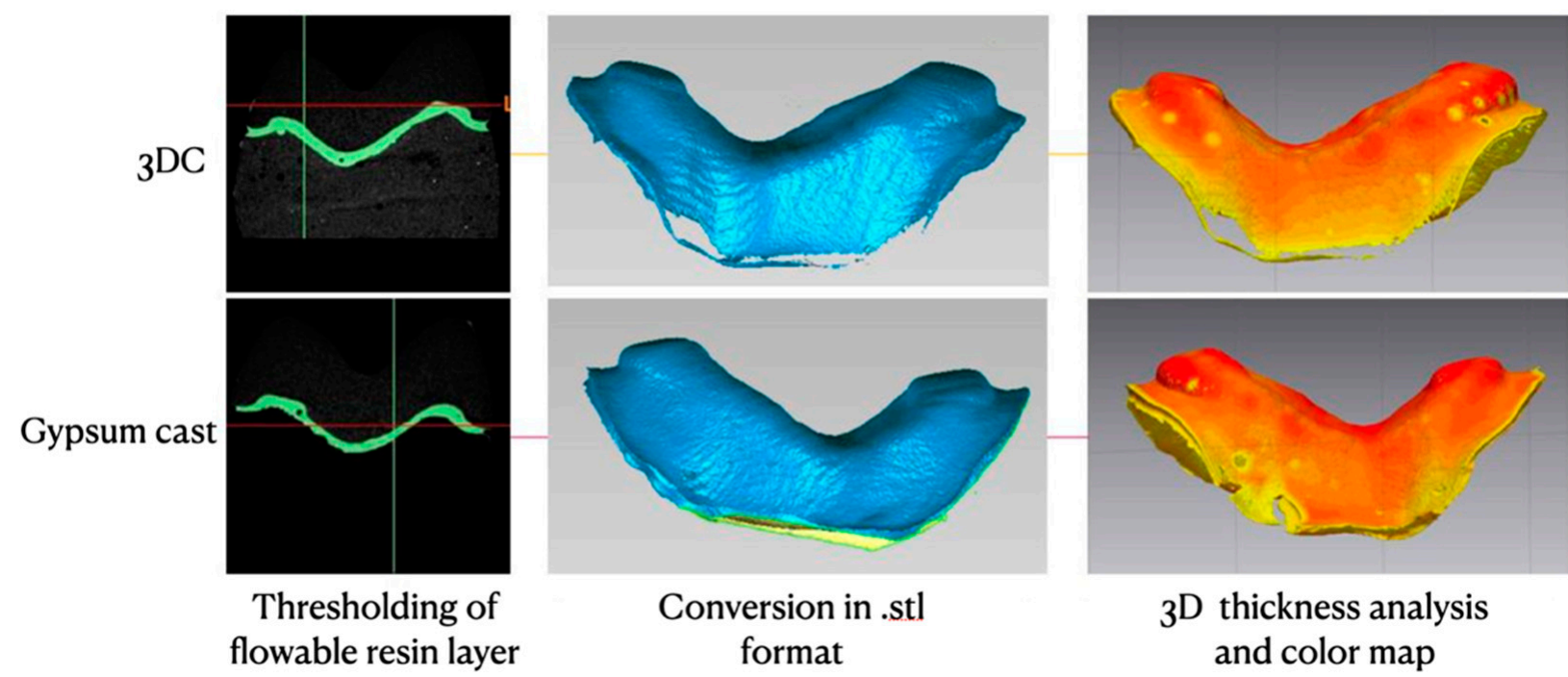

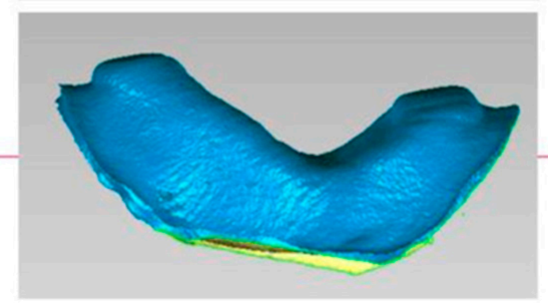

Conversion in .stl format

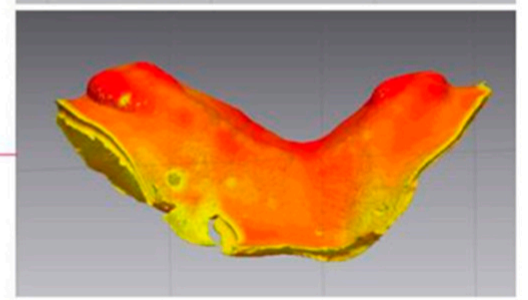

3D thickness analysis and color map

Figure 3. Same sample shown in Figure 2 interfacial analysis on 3DC and gypsum cast. Color map on the right of the picture represents cement thickness, scaling from yellow $(30 \mu \mathrm{m})$ to red $(300 \mu \mathrm{m})$ for visual representation.

\subsection{Statistical Analysis}

3D surface trueness of IOS and 3DCS compared to RS, as well as the interfacial fit of restorations over conventional and 3DC were analyzed by Student's $t$-test. A value of tolerance $p<0.05$ was set for significance. Statistical analyses were performed using Stata software (ver. 12.0; StataCorp, College Station, TX, USA).

\section{Results}

Average 3D surface trueness \pm standard deviation, expressed in $\mu \mathrm{m}$, of IOS and 3DCS compared to the RS is shown in Table 1 . No significant differences were reported by the software between all tested models and RS $(p>0.05)$.

Table 1. Average 3D surface trueness \pm standard deviation, expressed in $\mu \mathrm{m}$, of IOS and 3DCS compared to RS.

\begin{tabular}{cc}
\hline Cast & 3D Surface Trueness $(\mu \mathrm{m})$ \\
\hline IOS & $11.56 \pm 8.13$ \\
3DCS & $17.01 \pm 9.73$ \\
\hline
\end{tabular}


Mean marginal and internal interfacial adaptation data \pm standard deviation, expressed in $\mu \mathrm{m}$, are presented in Table 2 . Both internal and marginal fit differed significantly between 3DC group and conventional cast group $(p \leq 0.001)$. Marginal adaptation resulted significantly better (lower gap) than internal adaptation for both analyzed casts $(p<0.001)$.

Table 2. Mean marginal and internal interfacial adaptation data \pm standard deviation, expressed in $\mu \mathrm{m}$ for conventional casts and 3DC.

\begin{tabular}{ccc}
\hline Type of Cast & $\begin{array}{c}\text { Marginal Adaptation } \\
(\boldsymbol{\mu \mathrm { m } )})\end{array}$ & $\begin{array}{c}\text { Internal Adaptation } \\
(\boldsymbol{\mu \mathrm { m } )})\end{array}$ \\
\hline Gypsum & $135.78 \pm 30.85$ & $212.31 \pm 28.35$ \\
3DC & $57.63 \pm 22.24$ & $144.55 \pm 24.95$ \\
\hline
\end{tabular}

\section{Discussion}

The use of digital technologies and 3D printing in restorative adhesive dentistry has numerous advantages. However, there is still controversy if it could be a better alternative to conventional impressions. Ender et al. recently found, with a new in vivo protocol, that the highest precision belonged to the conventional impression extra orally digitized with a laboratory scanner, with an average deviation of $10 \mu \mathrm{m}[21,34]$. However, in a recent systematic review, Joda et al. [35] concluded that the efficacy of a full digital workflow is unclear due to a dearth of evidence.

Note that most of the studies in the literature are held in vitro with ideal conditions, therefore avoiding clinical problems such as blood and saliva control. The present ex vivo model is meant to deal with real conditions that might affect IOS and conventional impression taking, in order to assess their reliability. STL files were compared with a three-dimensional overlapping method that has already been widely used and described by previous studies in literature, showing reliable results $[29,32,36]$.

Obtained results showed no significant differences in terms of surface trueness between tested scans and RS, so the first null hypothesis was accepted. This is in agreement with the study of Rhee et al. which evaluated the deviations in superimposed impressions, concluding that there was no superiority of any impression technique [37]. In a very recent systematic review on clinical trials, the majority of the selected studies followed similar materials and methods to compare digital and conventional procedures [38], ultimately concluding that conventional impressions are more accurate than digital impressions in vivo. However, it was also reported that significant evidence about digital technologies performances in vivo is not up to date, which might explain the discrepancy with the present study.

By contrast, the present study data showed a statistically significant difference between the tested physical casts concerning both marginal and internal adaptation of milled adhesive restorations; thus, the second null hypothesis was rejected.

Several studies already evaluated the internal and marginal fit of conventional fixed prosthesis restorations [39]. In the present study, interfacial fit was analyzed through micro-CT, which enables internal, non-destructive analysis of samples compared to traditional methods [40,41]. Previous micro-CT studies involved linear measurements on two-dimensional images, which limited the number of points measured and hampered generation of a reproducible reference, possibly introducing operator bias. The use of an automatic software thresholding and 3D thickness analysis of a flowable, yet highly radiopaque, cement layer was conducted in order to reduce operator biases.

According to the findings of the present study, 3DC showed both marginal and internal interfacial fit values superior to those of gypsum casts. Indirect restorations were projected and milled starting from the same STL files from which 3DC were printed, confirming that $3 \mathrm{D}$ printing and restoration's CAD project were correctly performed. Moreover, due to the high precision shown, it is assumable that a digital workflow could benefit from the use of 3DC whenever a physical model is needed. 
The fit analysis yielded significantly higher internal gap values (144.55-212.31 $\mu \mathrm{m}$ average, respectively, for 3DC and gypsum casts) compared to marginal values (57.63-135.78 $\mu \mathrm{m}$ average, respectively, for 3DC and gypsum casts). This was expected, due to the digital spacing $(100 \mu \mathrm{m})$ applied in the CAM phase among axial walls of the preparations. Within the marginal area, where no spacing was applied, the gap values were comparable to those in prior studies conducted on chairside CAD/CAM conventional ceramic restorations [42,43]. Tsirogiannis et al.'s meta-analysis about ceramic crowns fit reported no significant difference between digital and conventional impression techniques, with values ranging from $63.3 \mu \mathrm{m}$ in vitro and $56.1 \mu \mathrm{m}$ in vivo for the digital workflow, to $58.9 \mu \mathrm{m}$ in vitro and $79.2 \mu \mathrm{m}$ in vivo for the conventional workflow [44]. The present study results suggest that adhesive restorations might have similar marginal gap behavior compared to conventional crowns, even if the margin design is deeply different. It must be highlighted that all data, for both adhesive restorations and conventional crowns, confirmed that both conventional and digital protocols are able to provide manufacts with clinically acceptable $(100-150 \mu \mathrm{m})$ interfacial gap [45].

A fact obtained in the present study that deserves attention is the discrepancy between surface trueness and fit analysis. No significant differences were reported in terms of surface deviation between gypsum casts and 3DC, but the fitting of the same restoration was significantly different between the two models. It is reasonable to assume that surfaces might be very similar overall, but even a small variation in a single area can affect the correct fit of the restoration. Thereafter, it is presumable that surface analysis alone might not be a reliable analysis method to determine the quality of a model.

The present study had some limitations. Extraoral scanners have been proved to be able to provide a reference for evaluating tooth preparation in vitro [46,47]. However, the present ex vivo model does not allow the scan of prepared teeth on patients with reference scanners. For this reason, IOS and 3DCS files can only be compared with the gypsum model scan (RS). Moreover, modern polyol and polyurethane resin casts could also be analyzed, as their performances seem higher than type IV conventional gypsum [48]. Another limitation was that measuring trueness only of master casts might be not enough to predict the restorations fitting. The addition of more parameters should be considered, in order to compare different methods of producing working casts effectively.

In spite of that, it is useful to compare direct digital workflows to conventional impressions as a reference, as analog impressions are still regarded as a gold standard in the field of fixed prosthodontics [38].

\section{Conclusions}

Within the limitations of the present study, we can conclude that in the manufacturing of adhesive indirect restorations, digital and conventional procedures generate casts that are not significantly different in terms of trueness. Marginal fit of chairside CAD/CAM adhesive restorations can be compared, in terms of value range, to conventional crown design and it is in the range of clinically acceptable. It is assumable that a direct digital workflow could benefit from the usage of 3DC, if necessary, to complete the manufacturing of an indirect adhesive restoration. Last, surface trueness analysis alone might not be a reliable method to determine the quality of a model. Further studies are needed to compare performances of these procedures in vivo, in order to define a specific gold-standard protocol for CAD/CAM chairside adhesive restorations.

Author Contributions: Conceptualization, D.B.; methodology, D.P., M.A.; software A.B., E.A.V.; validation A.C.; formal analysis M.L.V.; investigation G.F., E.I.; data curation A.B.; writing—original draft preparation, A.B.; writing —review and editing, R.M.T., D.B.; supervision, N.S. All authors have read and agreed to the published version of the manuscript.

Funding: This research received no external funding.

Institutional Review Board Statement: The study was granted ethics approval by the local ethics committee at the Dental School, University of Turin (DS-2018_No. 001). 
Informed Consent Statement: Informed consent was obtained from all subjects involved in the study.

Conflicts of Interest: The authors declare no conflict of interest.

\section{References}

1. Van Noort, R. The future of dental devices is digital. Dent. Mater. 2012, 28, 3-12. [CrossRef]

2. Wittneben, J.-G.; Wright, R.F.; Weber, H.-P.; Gallucci, G.O. A systematic review of the clinical performance of CAD/CAM single-tooth restorations. Int. J. Prosthodont. 2009, 22, 466-471.

3. Fasbinder, D.J. Computerized technology for restorative dentistry. Am. J. Dent. 2013, 26, 115-120.

4. Revilla-León, M.; Olea-Vielba, M.; Esteso-Saiz, A.; Martínez-Klemm, I.; Özcan, M. Marginal and Internal Gap of Handmade, Milled and 3D Printed Additive Manufactured Patterns for Pressed Lithium Disilicate Onlay Restorations. Eur. J. Prosthodont. Restor. Dent. 2018, 26, 31-38. [CrossRef] [PubMed]

5. Liu, Q.; Leu, M.C.; Schmitt, S.M. Rapid prototyping in dentistry: Technology and application. Int. J. Adv. Manuf. Technol. 2006, 29, 317-335. [CrossRef]

6. Nedelcu, R.; Olsson, P.; Nyström, I.; Rydén, J.; Thor, A. Accuracy and precision of 3 intraoral scanners and accuracy of conventional impressions: A novel in vivo analysis method. J. Dent. 2018, 69, 110-118. [CrossRef]

7. Kuhr, F.; Schmidt, A.; Rehmann, P.; Wöstmann, B. A new method for assessing the accuracy of full arch impressions in patients. J. Dent. 2016, 55, 68-74. [CrossRef]

8. Hamalian, T.A.; Nasr, E.; Chidiac, J.J. Impression Materials in Fixed Prosthodontics: Influence of Choice on Clinical Procedure. J. Prosthodont. 2011, 20, 153-160. [CrossRef] [PubMed]

9. Papadiochos, I.; Papadiochou, S.; Emmanouil, I. The Historical Evolution of Dental Impression Materials. J. Hist. Dent. 2017, 65, 79-89. [PubMed]

10. Rudolph, H.; Graf, M.R.S.; Kuhn, K.; Rupf-Köhler, S.; Eirich, A.; Edelmann, C.; Quaas, S.; Luthardt, R.G. Performance of dental impression materials: Benchmarking of materials and techniques by three-dimensional analysis. Dent. Mater. J. 2015, 34, 572-584. [CrossRef] [PubMed]

11. Barabanti, N.; Preti, A.; Vano, M.; Derchi, G.; Mangani, F.; Cerutti, A. Indirect composite restorations luted with two different procedures: A ten years follow up clinical trial. J. Clin. Exp. Dent. 2015, 7, e54-e59. [CrossRef] [PubMed]

12. Abduo, J.; Sambrook, R.J. Longevity of ceramic onlays: A systematic review. J. Esthet. Restor. Dent. 2018, 30, 193-215. [CrossRef] [PubMed]

13. Caputi, S.; Varvara, G. Dimensional accuracy of resultant casts made by a monophase, one-step and two-step, and a novel two-step putty/light-body impression technique: An in vitro study. J. Prosthet. Dent. 2008, 99, 274-281. [CrossRef]

14. Christensen, G.J. The state of fixed prosthodontic impressions: Room for improvement. J. Am. Dent. Assoc. 2005, 136, 343-346. [CrossRef] [PubMed]

15. Schepke, U.; Meijer, H.J.A.; Kerdijk, W.; Cune, M.S. Digital versus analog complete-arch impressions for single-unit premolar implant crowns: Operating time and patient preference. J. Prosthet. Dent. 2015, 114, 403-406.e1. [CrossRef]

16. Haralur, S.B.; Toman, M.S.; Al-Shahrani, A.A.; Al-Qarni, A.A. Accuracy of Multiple Pour Cast from Various Elastomer Impression Methods. Int. J. Dent. 2016, 2016, 7414737. [CrossRef]

17. Memari, Y.; Mohajerfar, M.; Armin, A.; Kamalian, F.; Rezayani, V.; Beyabanaki, E. Marginal Adaptation of CAD/CAM All-Ceramic Crowns Made by Different Impression Methods: A Literature Review. J. Prosthodont. Off. J. Am. Coll. Prosthodont. 2019, 28, e536-e544. [CrossRef]

18. Patzelt, S.B.M.; Lamprinos, C.; Stampf, S.; Att, W. The time efficiency of intraoral scanners: An in vitro comparative study. J. Am. Dent. Assoc. 2014, 145, 542-551. [CrossRef]

19. Abduo, J.; Elseyoufi, M. Accuracy of Intraoral Scanners: A Systematic Review of Influencing Factors. Eur. J. Prosthodont. Restor Dent. 2018, 26, 101-121.

20. Güth, J.-F.; Runkel, C.; Beuer, F.; Stimmelmayr, M.; Edelhoff, D.; Keul, C. Accuracy of five intraoral scanners compared to indirect digitalization. Clin. Oral Investig. 2017, 21, 1445-1455. [CrossRef]

21. Ender, A.; Zimmermann, M.; Attin, T.; Mehl, A. In vivo precision of conventional and digital methods for obtaining quadrant dental impressions. Clin. Oral Investig. 2016, 20, 1495-1504. [CrossRef] [PubMed]

22. Mangano, F.; Gandolfi, A.; Luongo, G.; Logozzo, S. Intraoral scanners in dentistry: A review of the current literature. BMC Oral Health 2017, 17, 149. [CrossRef]

23. Ahlholm, P.; Sipilä, K.; Vallittu, P.; Jakonen, M.; Kotiranta, U. Digital Versus Conventional Impressions in Fixed Prosthodontics: A Review. J. Prosthodont. Off. J. Am. Coll. Prosthodont. 2018, 27, 35-41. [CrossRef] [PubMed]

24. Berrendero, S.; Salido, M.P.; Ferreiroa, A.; Valverde, A.; Pradíes, G. Comparative study of all-ceramic crowns obtained from conventional and digital impressions: Clinical findings. Clin. Oral Investig. 2019, 23, 1745-1751. [CrossRef] [PubMed]

25. Felton, D.A.; Kanoy, B.E.; Bayne, S.C.; Wirthman, G.P. Effect of in vivo crown margin discrepancies on periodontal health. J. Prosthet. Dent. 1991, 65, 357-364. [CrossRef]

26. Lang, N.P.; Kiel, R.A.; Anderhalden, K. Clinical and microbiological effects of subgingival restorations with overhanging or clinically perfect margins. J. Clin. Periodontol. 1983, 10, 563-578. [CrossRef] [PubMed]

27. Al-Imam, H.; Gram, M.; Benetti, A.R.; Gotfredsen, K. Accuracy of stereolithography additive casts used in a digital workflow. J. Prosthet. Dent. 2018, 119, 580-585. [CrossRef] [PubMed] 
28. Kasparova, M.; Grafova, L.; Dvorak, P.; Dostalova, T.; Prochazka, A.; Eliasova, H.; Prusa, J.; Kakawand, S. Possibility of reconstruction of dental plaster cast from 3D digital study models. Biomed. Eng. Online 2013, 12, 49. [CrossRef]

29. Cho, S.-H.; Schaefer, O.; Thompson, G.A.; Guentsch, A. Comparison of accuracy and reproducibility of casts made by digital and conventional methods. J. Prosthet. Dent. 2015, 113, 310-315. [CrossRef] [PubMed]

30. Kurz, M.; Attin, T.; Mehl, A. Influence of material surface on the scanning error of a powder-free 3D measuring system. Clin. Oral Investig. 2015, 19, 2035-2043. [CrossRef]

31. Heshmati, R.H.; Nagy, W.W.; Wirth, C.G.; Dhuru, V.B. Delayed linear expansion of improved dental stone. J. Prosthet. Dent. 2002, 88, 26-31. [CrossRef] [PubMed]

32. Gan, N.; Xiong, Y.; Jiao, T. Accuracy of Intraoral Digital Impressions for Whole Upper Jaws, Including Full Dentitions and Palatal Soft Tissues. PLoS ONE 2016, 11, e0158800. [CrossRef] [PubMed]

33. Malik, J.; Rodriguez, J.; Weisbloom, M.; Petridis, H. Comparison of Accuracy Between a Conventional and Two Digital Intraoral Impression Techniques. Int. J. Prosthodont. 2018, 31, 107-113. [CrossRef] [PubMed]

34. Ender, A.; Attin, T.; Mehl, A. In vivo precision of conventional and digital methods of obtaining complete-arch dental impressions. J. Prosthet Dent. 2016, 115, 313-320. [CrossRef] [PubMed]

35. Joda, T.; Zarone, F.; Ferrari, M. The complete digital workflow in fixed prosthodontics: A systematic review. BMC Oral Health 2017, 17, 124. [CrossRef]

36. Pesce, P.; Pera, F.; Setti, P.; Menini, M. Precision and Accuracy of a Digital Impression Scanner in Full-Arch Implant Rehabilitation. Int. J. Prosthodont. 2018, 31, 171-175. [CrossRef]

37. Rhee, Y.-K.; Huh, Y.-H.; Cho, L.-R.; Park, C.-J. Comparison of intraoral scanning and conventional impression techniques using 3-dimensional superimposition. J. Adv. Prosthodont. 2015, 7, 460-467. [CrossRef]

38. Giachetti, L.; Sarti, C.; Cinelli, F.; Russo, D.S. Accuracy of Digital Impressions in Fixed Prosthodontics: A Systematic Review of Clinical Studies. Int. J. Prosthodont. 2020, 33, 192-201. [CrossRef]

39. Contrepois, M.; Soenen, A.; Bartala, M.; Laviole, O. Marginal adaptation of ceramic crowns: A systematic review. J. Prosthet. Dent. 2013, 110, 447-454.e10. [CrossRef]

40. Mostafa, N.Z.; Ruse, N.D.; Ford, N.L.; Carvalho, R.M.; Wyatt, C.C.L. Marginal Fit of Lithium Disilicate Crowns Fabricated Using Conventional and Digital Methodology: A Three-Dimensional Analysis. J. Prosthodont. 2018, 27, 145-152. [CrossRef] [PubMed]

41. Seelbach, P.; Brueckel, C.; Wöstmann, B. Accuracy of digital and conventional impression techniques and workflow. Clin. Oral Investig. 2013, 17, 1759-1764. [CrossRef] [PubMed]

42. Renne, W.; Wolf, B.; Kessler, R.; McPherson, K.; Mennito, A.S. Evaluation of the Marginal Fit of CAD/CAM Crowns Fabricated Using Two Different Chairside CAD/CAM Systems on Preparations of Varying Quality. J. Esthet. Restor. Dent. 2015, 27, 194-202. [CrossRef]

43. Neves, F.D.; Prado, C.J.; Prudente, M.S.; Carneiro, T.A.; Zancopé, K.; Davi, L.R.; Mendonca, G.; Cooper, L.F.; Soares, C. Microcomputed tomography evaluation of marginal fit of lithium disilicate crowns fabricated by using chairside CAD/CAM systems or the heat-pressing technique. J. Prosthet. Dent. 2014, 112, 1134-1140. [CrossRef] [PubMed]

44. Tsirogiannis, P.; Reissmann, D.R.; Heydecke, G. Evaluation of the marginal fit of single-unit, complete-coverage ceramic restorations fabricated after digital and conventional impressions: A systematic review and meta-analysis. J. Prosthet. Dent. 2016, 116, 328-335.e2. [CrossRef] [PubMed]

45. Syrek, A.; Reich, G.; Ranftl, D.; Klein, C.; Cerny, B.; Brodesser, J. Clinical evaluation of all-ceramic crowns fabricated from intraoral digital impressions based on the principle of active wavefront sampling. J. Dent. 2010, 38, 553-559. [CrossRef]

46. Koch, G.K.; Gallucci, G.O.; Lee, S.J. Accuracy in the digital workflow: From data acquisition to the digitally milled cast. J. Prosthet. Dent. 2016, 115, 749-754. [CrossRef]

47. Flügge, T.V.; Schlager, S.; Nelson, K.; Nahles, S.; Metzger, M.C. Precision of intraoral digital dental impressions with iTero and extraoral digitization with the iTero and a model scanner. Am. J. Orthod. Dentofac. Orthop. 2013, 144, 471-478. [CrossRef]

48. Tavarez, R.R.D.J.; Carvalhal, S.T.; Gomes, M.G.; Malheiros, A.S.; Gonçalves, L.M.; Filho, E.M.; Bandeca, M.C.; Patil, S. Assessment of a Synthetic Type IV Cast and a Resin Polyol Used in the Fabrication of Dental Models. J. Contemp Dent. Pr. 2016, 17, 160-164. [CrossRef] 